\title{
O DEBATE HART-DWORKIN E O DILEMAN DE COLEMAN: O QUE A LITERATURA TEM A DIZER SOBRE A RELAÇÃO DIREITO E MORAL ${ }^{1}$
}

THE HART-DWORKIN DEBATE AND THE COLEMAN DILEMMA: WHAT DOES LITERATURE SAY ABOUT THE RELATION BETWEEN LAW AND MORALITY?

EL DEBATE HART-DWORKIN Y EL DILEMA DE COLEMAN: ¿QUÉ LA LITERATURA DICE
SOBRE LA RELACIÓN DERECHO Y MORAL?

Lara Santos Zangerolame Taroco ${ }^{2}$ Nelson Camatta Moreira ${ }^{3}$

Resumo: As questões relativas à relação entre o direito e a moral inspiram diversos debates teóricos, os quais influenciam sobremaneira os paradigmas dominantes na teoria do direito. Dentre esses diálogos, merece especial destaque o promovido entre Hart e Dworkin, justamente porque evidencia a concepção do positivismo jurídico de Hart e, consequentemente, a oposição feita por Dworkin, principalmente no que diz respeito à discricionariedade.

1 Este artigo reproduz, parcialmente, as pesquisas elaboradas a partir do Grupo de Pesquisa Hermenêutica Jurídica e Jurisdição Constitucional (CNPQ), da Faculdade de Direito de Vitória (FDV-ES, Brasil)

2 Mestranda em Direitos e Garantias Fundamentais pela Faculdade de Direito de Vitória (FDV-ES, Brasil). Graduada em Direito pela Faculdade de Direito de Vitória. Membro do Grupo de Pesquisa Hermenêutica Jurídica e Jurisdição Constitucional (CNPQ) do Programa de Pós-Graduação Stricto Sensu da mesma instituição. Advogada. Contato: larasantosz@hotmail.com.

3 Pós-doutorado em Direito (UNIVERSIDAD DE SEVILLA), com bolsa da Coordenação de Aperfeiçoamento de Pessoal de Nível Superior (CAPES, Brasil) - Processo POS_DOC 99999.000348/2015-05; Doutorado em Direito (UNISINOS-RS), com estágio de pesquisa anual na Universidade de Coimbra, com bolsa CAPES. Líder do Grupo de Pesquisa CNPQ "Hermenêutica Jurídica e Jurisdição Constitucional", da FDV-ES. Professor da Programa de Pós-graduação Stricto Sensu (Doutorado e Mestrado) e da Graduação em Direito da FDV-ES. Membro Honorário da Rede Brasileira Direito e Literatura. Contato: nelsoncmoreira@hotmail.com. 
Cumpre, portanto, realizar o enfrentamento desta temática a partir da narrativa literária da obra "A mancha humana", de Philip Roth, a fim de perquirir quais as possíveis contribuições que a literatura pode ofertar a partir desse enredo para revisitar o debate entre Hart e Dworkin, especialmente no que diz respeito às relações entre direito e moral e discricionariedade. Palavras-chave: Direito e moral; justificação moral do direito; A Mancha humana.

Abstract: Questions relating to the relationship between law and morality have inspired various theoretical debates, which have greatly influenced the dominant paradigms in law theory. Among these dialogues, special attention is given to the debate between Hart and Dworkin, because it demonstrates the concept of legal positivism of Hart and consequently, the opposition made by Dworkin, particularly with regard to discretionarity. It is therefore necessary to face this issue based on the literary narrative of Philip Roth's, "The Human Stain", in order to investigate the possible contributions that literature can offer, based on this plot to revisit the debate between Hart and Dworkin, especially with regard to the relationship between law and morality and discretionarity. Keywords: Law and morality; moral justification; The Human Stain.

Resumen: Las cuestiones relativas a la relación entre el derecho y la moral inspiran diversos debates teóricos, los cuales influyen sobremanera en los paradigmas dominantes en la teoría del derecho. Entre esos diálogos, merece especial destaque el promovido entre Hart y Dworkin, justamente porque evidencia la concepción del positivismo jurídico de Hart y, consecuentemente, la oposición hecha por Dworkin, principalmente con relación a la discrecionalidad. Se debe, por lo tanto, realizar el enfrentamiento de esta temática a partir de la narrativa literaria de la obra "La mancha humana", de Philip Roth, con el fin de examinar cuales son las posibles contribuciones que la literatura puede ofrecer a partir de esa trama para revisar el debate entre Hart y Dworkin, especialmente en lo que se refiere a las relaciones entre derecho, moral y discrecionalidad. Palabras-clave: Derecho y moral; justificación moral del derecho; La Mancha humana.

\section{INTRODUÇÃO}

discussão acerca da relação entre direito e moral, ainda hoje, apresenta-
se como uma das mais controvertidas no âmbito jurídico, razão pela
qual inspirou diversos debates entre juristas com compreensões
distintas sobre a interação desses dois campos. Justice for Hedgehogs - "Justiça
para ouriços" -, lançado originalmente em 2011 , foi a última obra publicada em 
vida por Ronald Dworkin e retoma esta temática em capítulo específico, o que só reforça a atualidade da questão, ao passo que também permite recobrar o debate entre este autor e Herbert L. A. Hart.

O embate entre as compreensões destes dois juristas mostra-se profícuo para a teoria do direito, tendo em vista que se trata de paradigmas em disputa para informar o que vem a ser, inclusive, o próprio direito. Constitui, portanto, contribuição relevante para estruturar tanto uma crítica ao positivismo de Hart, direcionada por Dworkin, quanto para estimular reflexões críticas sobre o conceito de "justificação moral" apresentado por Dworkin e questionado por Hart.

Para completar esse cenário, cabe agregar as contribuições da literatura, que oferece uma interessante instância para se refletir a respeito tanto da perspectiva de Hart, quanto de Dworkin a respeito das relações entre direito e moral. Assim, proporciona, por meio da obra "A mancha humana", de Philip Roth, a elucidação de diversos problemas decorrentes do enfrentamento e da interpenetração desses dois âmbitos.

A partir da narrativa apresentada pelo autor norte-americano, Philip Roth, são suscitadas questões que podem iluminar a abordagem, por vezes, insuficiente quando realizada somente a partir do prisma jurídico. O afastamento de um professor universitário pautada em argumentos totalmente dissociados dos fatos, um julgamento que leva em conta aspectos da vida pessoal do profissional, questões morais e, sobretudo, uma pretensão de vingança retomada em momento oportuno, é o cenário do dilema de Coleman, personagem de Roth no enredo de "A mancha humana".

Para realizar essa abordagem, cumpre tratar em um primeiro momento das aproximações entre direito e literatura, perpassando pelas funções de cada um desses âmbitos, bem como suas respectivas dificuldades. Já em momento seguinte, cabe abordar, mediante os aportes teóricos fornecidos pelo debate de Hart e Dworkin, como pode ser estabelecida a relação entre o direito e a moral, bem como quais os dilemas que essa aproximação enseja.

Tudo isso com vistas a traçar as pré-compreensões necessárias para analisar a proposta motriz do presente estudo, desenvolvida no último capítulo, qual seja, a 
de perquirir quais as contribuições ofertadas pela literatura, a partir do enredo de "A mancha humana", de Philip Roth, para revisitar o debate entre Hart e Dworkin, especialmente no que diz respeito às relações entre direito e moral.

\section{A obra "a mancha humana" e o repertório literário polêmico de Philip Roth}

O romancista norte-americano de origem judaica, Philip Roth, explora em sua obra os muitos dilemas de assimilação e identidade dos judeus dos Estados Unidos. Aos 26 anos, quando ainda desconhecido, publicou seus primeiros contos e desde logo foi confrontado com cartas enviadas aos editores, as quais exigiam providências em relação ao conteúdo de suas narrativas, questionando: "o que está sendo feito para calar esse homem?"4. A razão desse frisson se deu em grande parte pela publicação do conto "O defensor da fé", na revista The New Yorker em 1959.

A polêmica narrativa acompanha o progresso moral e emocional de um sargento judeu justo e imparcial, confrontado com questionamentos levantados por um jovem soldado judeu, que ao fim acusa o sargento de antissemitismo ${ }^{5}$. A reação da comunidade judaica, justificada principalmente em função da exposição de dilemas deste grupo para a sociedade gentia, fez com que a The New Yorker elaborasse uma carta padrão para enviar como resposta as tantas correspondências recebidas.

Um rabino, então vocalizador da Liga Antidifamação da B'nai B'rith, ao pronunciarse, destacou que "se o conto fosse veiculado - em hebraico - em uma revista ou jornal israelense, teria sido julgado exclusivamente do ponto de vista

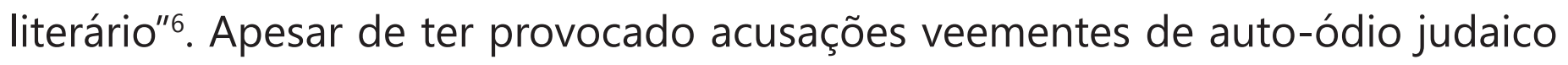
e antissemitismo, a pretensão de Roth, como destaca Claudia Pierpont Roth, era ser criticado exclusivamente do ponto de vista literário, tanto porque, para ele, já restava claro que:

(...) as pessoas leem Anna Karenina sem concluir que o adultério é um traço russo; Madame Bovary não leva leitores a condenar a moral das mulheres provincianas francesas em massa. Ele estava fazendo literatura, não sociologia ou - na útil expressão de Bellow - relações públicas.

4 ROTH, Philip. Reading myself and others. Nova York: Vintage International, 2010, p.16.

5 ROTH, Philip. Reading myself and others. Nova York: Vintage International, 2010, p.18.

6 ROTH, Philip. Reading myself and others. Nova York: Vintage International, 2010, p.17. 
Aspirava aos mais elevados ideais artísticos e achava que, se conseguisse se explicar, com bastante cuidado, as pessoas entenderiam. ${ }^{7}$

Entretanto, apesar dessa despretensão, seus contos e romances extrapolaram a crítica literária e tomaram, quase sempre, repercussão pessoal e política. São essas faíscas, as quais transcendem a apreciação dos estudos literários, que possibilitam o alinhamento da produção de Philip Roth com a proposta do presente estudo.

Dentre as obras de Roth, o romance "A mancha humana" foi selecionado por tratar de distintos dilemas morais vividos por Coleman Silk, por seu julgamento igualmente marcado por questões morais e seu consequente afastamento, praticamente inevitável frente à sua exposição pública. Assim, aproximação com a obra literária se faz justamente no intento de desfrutar do potencial associativo ${ }^{8}$, que auxilia na compreensão da temática relacionada ao direito e à moral e transforma o enredo desta história em instância privilegiada para demonstrar as consequências e os conceitos apresentados por Hart e Dworkin.

Ao lado de "Pastoral americana" e "Casei com um comunista", "A mancha humana" compõe a trilogia de Philip Roth sobre a vida do pós-guerra norte-americano. Neste enredo, a crítica corrosiva ao moralismo, característica das narrativas de Roth, toma forma inicial a partir do escândalo sexual envolvendo o presidente Clinton, em 1998, para depois materializar-se também na vida do professor universitário Coleman Silk.

O "espírito persecutório"9 arrebata então toda sociedade, "no Congresso, na imprensa, e nas televisões os farisaicos paladinos encartados da moral e dos bons costumes, sôfregos por censurar, deplorar e punir, apareciam em todo lado numa estridente campanha moralizadora"10.

Nesse mesmo ano de histeria moralizadora, Coleman Silk é um professor de estudos clássicos no Athena College, na Nova Inglaterra, há mais de vinte anos, além de ter sido reitor da mesma instituição. Aos setenta anos é obrigado a se afastar de suas atividades acadêmicas em função de uma acusação de racismo,

7 ROTH, Claudia Pierpont. Roth libertado: o escritor e seus livros. São Paulo: Companhia das Letras, 2015, p,17.

8 MOISÉS, Massaund. Literatura: mundo e forma. São Paulo: Universidade de São Paulo, 1990, p.195.

9 ROTH, Philip. A mancha humana. 10. ed. Alfragide: Dom Quixote, 2014, p.14.

10 ROTH, Philip. A mancha humana. 10. ed. Alfragide: Dom Quixote, 2014, p.15. 
e de posteriores acusações envolvendo um comportamento inadequado em sua vida privada.

A trama começa quando o professor, ao realizar a chamada, nota a ausência contínua de duas alunas, e utiliza a palavra "spooks" para se referir às ausentes, o que repercutiu de forma negativa, uma vez que o termo é ambíguo e ao mesmo tempo que significa "fantasma", também é palavra de baixo calão utilizada para ofender pessoas negras.

A abordagem literária se faz essencial para compreender a discussão proposta por esta análise, principalmente porque cuida de evidenciar uma série de julgamentos inteiramente morais realizados em face de Coleman, que operam de forma discricionária. Ao se dirigir ao reitor, em sua defesa, Coleman tenta explicar o duplo sentido da expressão:

(...) eu estava a referir-me à sua natureza porventura ectoplasmástica. Isso não é evidente? Essas duas estudantes não tinham comparecido a uma única aula. Essa era a única coisa que eu sabia a seu respeito. Usei a palavra no seu significado habitual e principal: espectro ou fantasma. Considere o contexto: elas existem ou são fantasmas? A acusação de racismo é espúria. É absurda. Os meus colegas sabem que é absurda e os meus alunos sabem que é absurda. ${ }^{11}$

Quando afastado, o professor chega a perguntar-se diversas vezes se sua conduta estava sendo julgada de acordo com o direito ou de acordo com os padrões morais da sociedade. Isso porque, fatos de sua vida privada, que nada tinham a ver com o ocorrido, vieram à tona e contribuíram para o seu ostracismo da Universidade.

A pressão de organizações estudantis e grupos ativistas voltados para o combate do racismo deram visibilidade à reclamação realizada pelas alunas. Ao mesmo tempo, o clamor social também afastou de Coleman qualquer apoio por parte de seus pares, o que gerou mais indignação ao personagem, tendo em vista que, quando ocupou o cargo de reitor, foi o primeiro a contratar um professor negro para lecionar na universidade.

A dimensão simbólica que acompanha toda trama parece complicar-se a medida em que Coleman promove sua defesa. Até mesmo suas boas ações passam a ser

11 ROTH, Philip. A mancha humana. 10. ed. Alfragide: Dom Quixote, 2014, p.19 
obnubiladas pelo presente escândalo. Nesse cenário, a literatura, como espaço da manifestação livre de todas as metáforas, é locus privilegiado de análise.

A partir disso, pertine questionar desde já: quanta realidade se encontra nesta ficção e o quanto essa ficção também não reflete a realidade? ${ }^{12}$. Este é o questionamento inicial que justifica a primeira razão pela qual esta produção literária pode contribuir para as discussões acerca da autonomia do direito frente ao discurso predatório da moral, na medida em que elucida o enlace e os limites da ficção e da realidade.

Como suscitou o próprio Roth ${ }^{13}$, "um problema mais intrigante é como ele [o escritor] escreve a respeito daquilo que não aconteceu - como introduz elementos hipotéticos ou imaginados naquilo que é inspirado e controlado pela lembrança, e como o relembrado traz à tona a fantasia que dá forma a seu trabalho".

Cabe destacar que a utilização da literatura neste estudo não visa traçar com precisão o caminho a ser percorrido para a resolução e trato desta temática tão complexa, mas, sobretudo, tem por objetivo destacar o aspecto problematizador instigado pela literatura. Tanto por isso, a narrativa de Philip Roth foi selecionada, em virtude da pertinência da obra "A mancha humana" com a temática jurídica em comento, e também pelo repertório literário do autor, que como romancista norte-americano de origem judaica abordou temáticas consideradas polêmicas e controversas.

Dessa forma, é mediante a análise do direito na literatura, voltado "para a formulação e a elucidação das principais questões relativas à justiça, à lei e ao poder"14, que se pretende enfrentar a questão das relações entre direito e moral, expostas pelo debate entre Dworkin e Hart, e a partir das contribuições da obra de Roth, cabendo em momento seguinte tratar como podem ser estabelecidas as relações entre o direito e a literatura.

\section{0 esqueleto reanimado e as relações (perigosas) entre o direito e a literatura}

A edição mais famosa do poema "The Grave", de Robert Blair ${ }^{15}$, foi publicada em

12 ROTH, Claudia Pierpont. Roth libertado: o escritor e seus livros. São Paulo: Companhia das Letras, 2015, p.45.

13 ROTH, Philip. Reading myself and others. Nova York: Vintage International, 2010, p.31.

14 OST, François. Contar a lei: as fontes do imaginário jurídico. São Leopoldo: UNISINOS, 2004, p.34.

15 BLAIR, Robert. The grave. New Heaven: Gale Ecco, 2010, p.2. 
1808 e contou com as ilustrações de William Blake. "The Skeleton Reanimated" O esqueleto reanimado -, uma das ilustrações de Blake, obteve especial destaque por ocupar a capa desta edição ${ }^{16}$. Nesta gravura, um esqueleto, que aparenta ter sido um corpo que um dia fora velado, aparece deitado, coberto por um pano, mas apesar da posição horizontal, o esqueleto projeta seu corpo para cima, como quem pretende levantar-se.

A razão desse despertar é ilustrada pela representação similar a um anjo, que com uma trombeta reanima os ossos que pertenceram a um corpo vivo. A proposta de Blake ilustra o poema de Robert Blair, que em versos narra os "horrores do túmulo"17, onde habitam os viajantes. $\mathrm{O}$ eu lírico de Blair pleiteia por um socorro ${ }^{18}$, que vem dos céus, para esses homens que estão onde não há "nada mais que silêncio"19.

Tanto a ilustração de Blake quanto o poema de Blair permitem, por meio da metáfora, compreender as relações que podem ser estabelecidas entre o direito e a literatura, principalmente no que diz respeito à proposta do direito contado e do direito analisado, elucidada por François $\mathrm{Ost}^{20}$. Isso porque esta relação é marcada por um constante atar e desatar, no qual o direito "vê-se abalado em suas certezas dogmáticas e é reconduzido às interrogações essenciais"21.

É precisamente esse reconduzir, aqui identificado com a reanimação do esqueleto, que ilustra a aproximação da literatura com o direito, que por meio de sua postura contestadora e exploradora de todas as soluções possíveis cuida de despertar o esqueleto dogmático do direito, tal qual a trombeta do anjo na gravura de Blake.

Essa inquietude instigada pela trombeta da "indisciplina literária"22 em seu empreendimento crítico, que faz não só que o esqueleto do direito desperte, mas define a relação entre esses campos como dialética. Por isso, é pautada pela construção e desconstrução, pois se a literatura "fragiliza os pretensos saberes

16 GILCHRIST, Alexandre. Life of William Blake. Cambridge: Cambridge University Press, 2010, p.10.

17 No original: "to paint the gloomy horrors of the tomb". BLAIR, Robert. The grave. New Heaven: Gale Ecco, 2010, p. 4.

18 No original: "These travelers meet, thy succours I implore, Eternal King". BLAIR, Robert. The grave. New Heaven: Gale Ecco, 2010, p. 4.

19 No original: "where nought but silence reigns, and night, dark night". BLAIR, Robert. The grave. New Heaven: Gale Ecco, 2010, p. 4.

20 OST, François. Contar a lei: as fontes do imaginário jurídico. São Leopoldo: UNISINOS, 2004, p.41.

21 OST, François. Contar a lei: as fontes do imaginário jurídico. São Leopoldo: UNISINOS, 2004, p.09.

22 OST, François. Contar a lei: as fontes do imaginário jurídico. São Leopoldo: UNISINOS, 2004, p.10. 
positivos sobre os quais o direito tenta apoiar sua própria positividade"23, essa crítica, quando acatada, também abre caminhos para a reformulação, ainda que de forma despretensiosa.

Cumpre destacar que, por diversas vezes, a literatura levanta questões e até mesmo propõe soluções, para temáticas que não são abarcadas pelos saberes acadêmicos, ou só são compreendidas tempos depois da previsão literária ${ }^{24}$. Por tudo isso, se a proposta é de aproximação entre o direito e a literatura, cabe antes identificar quatro diferenciações entre esses dois âmbitos apresentadas por François Ost.

A primeira delas é a de que, "enquanto a literatura libera os possíveis, o direito codifica a realidade, a institui por uma rede de qualificações convencionadas, a encerra num sistema de obrigações e interdições" 25 . A literatura por meio da abordagem libertária "não cessa de investir contra a fortaleza jurídica com suas salutares gargalhadas" 26 , principalmente quando se utiliza do cômico para seu empreendimento crítico.

Outra distinção diz respeito à própria função do direito e da literatura. A função social do direito "Ihe impõe estabilizar as expectativas e tranquilizar as angústias"27, razão da valorização da segurança jurídica como promessa a ser cumprida na modernidade. O êxito deste intento, quando logrado, repercute em uma concepção que usualmente nega a complexidade dos fenômenos sociais. Isso porque parte da tentativa de enclausuramento desses fenômenos em conceitos jurídicos, estáticos e anestesiando, que desvencilham a teoria da prática ${ }^{28}$.

O cenário se agrava quando o paradigma dominante no direito é estabelecido sob os auspícios de um "modelo liberal-individualista-normativista", predominante na dogmática jurídica brasileira ${ }^{29}$, que pode ser identificado pela "mentalidade

23 OST, François. Contar a lei: as fontes do imaginário jurídico. São Leopoldo: UNISINOS, 2004, p.15.

24 MOREIRA, Nelson Camatta; DE PAULA, Rodrigo. Lima Barreto: subcidadania, negação do estado de direito e constitucionalismo dirigente no Brasil. In: MOREIRA, Nelson Camatta. Direito e literatura e os múltiplos horizontes de compreensão pela arte. ljuí: UNIJUÍ, 2015, p.39.

25 OST, François. Contar a lei: as fontes do imaginário jurídico. São Leopoldo: UNISINOS, 2004, p.15.

26 OST, François. Contar a lei: as fontes do imaginário jurídico. São Leopoldo: UNISINOS, 2004, p.13.

27 OST, François. Contar a lei: as fontes do imaginário jurídico. São Leopoldo: UNISINOS, 2004, p.15.

28 SANCHEZ RUBIO, David. Crítica a una cultura estática y anestesiada de derechos humanos. Por una recuperación por las dimensiones constituyentes de la lucha por los derechos. Derechos y Libertades, Madrid: v. 33, 2015, p.125.

29 STRECK, Lenio Luiz. Hermenêutica Jurídica e(m) Crise: uma exploração hermenêutica da construção do Direi- 
legalista forjada em flagrante contradição com a realidade socioeconômica"30 pautada pela prevalência de uma burocracia "incapaz de perceber as razões dos conflitos sociais" 31 . Isso porque permanece arraigada ao ideal de segurança jurídica, dentre outros, que impossibilita de acompanhar a dinamicidade dos fenômenos sociais.

Em caminho diverso, a literatura, "livre dessas exigências, cria, antes de tudo, a surpresa: ela espanta, deslumbra, perturba, sempre desorienta"32. Nesta altura, cabe perquirir quais as funções da literatura, tendo em vista ser este o segundo ponto de distinção em relação ao direito.

Inúmeras são as funções da literatura e mais diversos são os objetivos dos estudos literários. Ainda, o poeta, ao ocupar o lugar de um fingidor, como descreve o poema de Fernando Pessoa, finge tão completamente que não só convence o leitor do enredo apresentado, mas também incita tantos outros sentimentos, que perfazem as funções da literatura.

Dentre estas, a título de exemplificação, cabe mencionar: a função reflexiva e de humanização do homem, pois é "o retrato vivo da alma humana, e a presença do espírito na carne"33; a função psicológica, marcada por "uma espécie de necessidade universal de produção e fruição de ficção e de fantasia"34; função de conscientização social e política do leitor ${ }^{35}$.

Afunçãohedonística, tendoemvistaque"aartedeve proporcionarprazer, retratando o belo"36; função catártica, que advém do papel que as tragédias desempenhavam no mundo grego, eficaz para "despertar no público os sentimentos de terror e piedade"37; a função heurística como gesto experimental de inaugurar novas realidades, "ao menos em alguns casos, portador de conhecimentos realmente novos" ${ }^{\prime 38}$; e a função de instrumento de comunicação e interação social, cumprindo to. 10. ed. Porto Alegre: Livraria do Advogado, 2011, p.63.

30 MOREIRA, Nelson Camatta. Direitos e garantias fundamentais e os tratados internacionais de direitos humanos. Belo Horizonte: Fórum, 2012, p.59.

31 LANES, Ely Vieitez. Laboratório de literatura. São Paulo: Estrutural, 1978, p.34.

32 OST, François. Contar a lei: as fontes do imaginário jurídico. São Leopoldo: UNISINOS, 2004, p.15.

33 LANES, Ely Vieitez. Laboratório de literatura. São Paulo: Estrutural, 1978, p.21.

34 CANDIDO, Antonio. A literatura e a formação do homem. São Paulo: Estrutural, 1972 , p.804.

35 MEIRA, Cécil. Introdução ao estudo da literatura. 5.ed. Belém: Imprensa Oficial do Estado, 1988, p.27.

36 MEIRA, Cécil. Introdução ao estudo da literatura. 5.ed. Belém: Imprensa Oficial do Estado, 1988, p.20.

37 MEIRA, Cécil. Introdução ao estudo da literatura. 5.ed. Belém: Imprensa Oficial do Estado, 1988, p.27.

38 OST, François. Contar a lei: as fontes do imaginário jurídico. São Leopoldo: UNISINOS, 2004 , p.15. 
"o papel de ser a expressão da cultura de uma comunidade"39.

A indicação de algumas funções não tem pretensão exaustiva, apenas elucida as tantas possibilidades iluminadas pela literatura, sendo pertinente a advertência de que, apesar destas funções, "deve esquecer-se imediatamente de resultado prático, que dela (a literatura) possa advir"40, pois o que prevalece são "variações imaginativas mais inesperadas"41, que explora "como laboratório experimental do humano, todas as saídas do caminho"42.

Dessa forma, sem condicionar a produção literária a resultados práticos preestabelecidos, Goethe ${ }^{43}$, no Prólogo de Fausto destaca:

Quem coloca o indivíduo insulado na ordem universal? Quem espalha um doce crepúsculo sobre o espírito absolvido em mediação austera? Quem semeia todas as belas flores da primavera ao longo da trilha pisada pelo amante? Quem despoja as folhas das árvores, onde pendiam inúteis, e as tece em coroas para distribuí-las aos méritos de todos os gêneros? Quem sustenta o Olimpo? Quem convoca a assembleia dos Deuses? O poder do homem, relevado no poeta.

A terceira diferença a ser evidenciada é que, enquanto a literatura produz personagens, compostos por características ambivalentes e de conduta imprevisível, o direito produz pessoas jurídicas, cujo "papel estereotipado, dotado de um estatuto de direitos e deveres convencionado"44, não abre espaço para outro discurso, senão o do comportamento padrão, que deve corresponder às expectativas predeterminadas. Esse ponto remete tanto à primeira distinção quando à segunda, pois é fruto da concepção pautada na segurança jurídica, refletida pela eliminação das possibilidades e consequente redução da complexidade dos fenômenos sociais.

A quarta distinção é uma decorrência de todas as anteriores, na medida em que o direito pretende realizar o "registro da generalidade e da abstração (a lei, dizem, é geral e abstrata)" 45 , adotando, por consequência, estatutos geralistas que

39 MEIRA, Cécil. Introdução ao estudo da literatura. 5.ed. Belém: Imprensa Oficial do Estado, 1988, p.20.

40 MEIRA, Cécil. Introdução ao estudo da literatura. 5.ed. Belém: Imprensa Oficial do Estado, 1988, p.18.

41 OST, François. Contar a lei: as fontes do imaginário jurídico. São Leopoldo: UNISINOS, 2004, p.15.

42 OST, François. Contar a lei: as fontes do imaginário jurídico. São Leopoldo: UNISINOS, 2004, p.15.

43 GOETHE, Johann Wolfgang von Fausto II: uma tragédia. 4.ed. São Paulo: Editora 34, 2015, p.85.

44 OST, François. Contar a lei: as fontes do imaginário jurídico. São Leopoldo: UNISINOS, 2004, p.16.

45 OST, François. Contar a lei: as fontes do imaginário jurídico. São Leopoldo: UNISINOS, 2004, p.18. 
englobam conceitos estáticos. A literatura, por sua vez, constitui-se no particular e no concreto, explora os elementos psicológicos das personagens de forma intimista e adota a descrição para compor e particularizar os enredos.

Ainda que para a prosa romântica a descrição tenha a finalidade de elevar e idealizar a personagem e para prosa realista cumpre o objetivo de retratar a personagem como ela realmente $e^{46}$, estes recursos, mesmo quando utilizados de modo distinto de acordo com o movimento literário, só evidenciam a concretude e a particularidade da narrativa literária. Entretanto, a atividade de singularizar pode ser o "caminho mais curto para chegar ao universal"47, pois a descrição intimista pode aproximar o leitor sobremaneira do personagem e de si mesmo.

Em que pese estas distinções, a complexidade que envolve esses dois campos de estudo não permite outra forma de interação senão a dinâmica da dialética. Isso porque, como elucida Ost, "o direito não se contenta em defender posições instituídas, mas exerce igualmente funções instituinte - o que supõe a criação imaginária de significações sociais-históricas novas"48, enquanto a literatura não se desprende totalmente do que está instituído.

Do contrário, alicerça-se muitas vezes em normas instituídas, que prendem o poeta e o romancista às regras de cada estilo ${ }^{49}$. Dessa forma, é justamente essa dialética, que não se prende somente às distinções de cada campo, mas sobretudo pelos dilemas em comum, que possibilita a aproximação do direito e da literatura.

Essa aproximação, que é estabelecida de forma transdisciplinar, ao passo que promove "a migração e articulação de conceitos e metodologias"50 desses dois saberes, o que é aqui reputado como essencial para possibilitar a análise das compreensões tanto de Hart, quanto de Dworkin, a respeito da relação direito e moral, a ser trabalhada no capítulo seguinte.

46 COELHO, Nelly Novaes. Literatura e ensino: uma problemática. 2.ed. São Paulo: Ática, 1992, p.214.

47 OST, François. Contar a lei: as fontes do imaginário jurídico. São Leopoldo: UNISINOS, 2004, p.19.

48 OST, François. Contar a lei: as fontes do imaginário jurídico. São Leopoldo: UNISINOS, 2004, p.20.

49 OST, François. Contar a lei: as fontes do imaginário jurídico. São Leopoldo: UNISINOS, 2004, p.21.

50 SANCHEZ RUBIO, David. Crítica a una cultura estática y anestesiada de derechos humanos. Por una recuperación por las dimensiones constituyentes de la lucha por los derechos. Derechos y Libertades, Madrid: v. 33, 2015, p.256. 


\section{O debate entre Hart e Dworkin: do conceito de direito à justificação moral}

Em novembro de 1961, na Faculdade de Direito da Universidade da Califórnia, em Berkeley, Albert Ehrenzweig promoveu o encontro de dois juristas, no intuito de discutir temáticas afetas ao pensamento positivista. Um deles era Hans Kelsen, que proferiu palestra a respeito dos tópicos principais de sua Teoria Geral do Direito, e o outro era Herbert L. A. Hart, responsável por tecer críticas aos tópicos explanados por Kelsen.

Dentre as conclusões e as divergências propiciadas pelo debate ${ }^{51}$, certamente a discussão a respeito das possibilidades de uma crítica moral ao direito é uma das mais instigantes, principalmente considerando a manifestação de Hart a respeito desta interrelação:

Finalmente, diria que em nosso debate não nos aprofundamos nessas questões bastante complexas envolvendo as relações lógicas entre Direito e Moral. Kelsen disse, contudo, que estava considerando novamente a questão das possíveis relações lógicas entre normas e, particularmente, a possibilidade de que uma norma possa logicamente entrar em conflito com uma outra. Mas devemos esperar muito sobre esse tema que considero o mais difícil.

São as contribuições de Hart e o consequente diálogo entre Hart e Dworkin que guiam a compreensão a respeito do direito e da moral proposta pelo presente estudo. A seleção desse debate em especial, apesar de outros igualmente importantes - vale mencionar o próprio debate com Kelsen ou o diálogo entre Devlin e Hart -, se deu em virtude das distinções teóricas entre Hart e Dworkin, as quais tratam de evidenciar uma possível mudança de paradigma no direito contemporâneo. Por assim ser, como ressalta César Rodríguez ${ }^{52}$ :

No es posible saber si la obra de Hart habría tenido mayor influencia sin las críticas de Dworkin, o si el pensamiento de éste habría llegado a ser predominante si no hubiese nacido bajo la sombra del hartiano. Lo que se indudable es el beneficio para la comunidade filosófica y jurídica que ha venido creciendo alrededor de este debate (...) la viva discusión Hart-Dworkin proporcionó las primeras herramientas para la comprensión de los cambios en la interpretación y la prática del derecho y continúa alimentando las creaciones de la teoría jurídica y el derecho constitucional.

51 HART, Hebert L. A. Visita a Kelsen. Lua Nova: Revista de Cultura e Política. São Paulo, 2005, p.9.

52 RODRÍGUEZ, César. La decisión judicial: el debate Hart-Dworkin. Bogotá: Siglo del Hombre, 1997, p.18. 
Frente a essa atualidade do debate, cabe explorar os pontos de divergência entre esses dois autores, tendo como destaque especial suas respectivas concepções a respeito da relação do direito com a moral, principalmente no que concerne à autonomia do discurso jurídico e sua justificação. A proposta de Hart, elucidada já nas primeiras passagens da obra "O conceito de direito", publicada em 1961, é justamente tratar da indagação: "o que é direito?"53.

Entretanto, não se trata apenas de uma questão de definição, mas sim de descrição de todo sistema jurídico e sua respectiva disposição. A partir dessa perspectiva, Hart elabora uma crítica à teoria positivista predominante na Inglaterra, cujo principal representante era John Austin, embasado pelos trabalhos de Jeremy Bentham do fim do século XVIII ${ }^{54}$.

A grande oposição promovida por Hart diz respeito ao conceito de direito empregado por Austin, qual seja "el derecho, em esta perpectiva, es el conjunto de órdenes respaldadas por amenazas dictadas por el soberano e ejercicio de su poder legislativo ilimitado" 55 . Mesmo compartilhando de algumas premissas medulares do positivismo de Bentham e Austin, a discordância de Hart diz respeito essencialmente a este conceito de direito.

Isso porque o critério de identificação das regras jurídicas é "o hábito dos cidadãos em obedecer a um soberano" 56 , o que não encontra esteio na teoria de Hart, em virtude de uma série de problemas. Dentre estes, cabe mencionar: a dificuldade de se identificar quem seria esse soberano e quais as suas ordens, por ser um critério muito amplo, também pode servir para identificar outras normas além das jurídicas, o que não traz qualquer progresso para uma teoria do direito que se propõe a limitar o conceito do que é jurídico.

Nesse sentido, para Hart "las normas jurídicas no son ordenes ocasionales que recibimos de parte de um legislador claramente identificado que nos conmina a cumplirlas bajo la ame-naza de um castigo" ${ }^{27}$. O modelo austiniano, portanto, repercute em diversas perguntas que não podem ser respondidas, e é a partir 53 HART, Herbert L. A. O conceito de direito. São Paulo: WMF Martins Fontes, 2009, p.1.

54 RODRÍGUEZ, César. La decisión judicial: el debate Hart-Dworkin. Bogotá: Siglo del Hombre, 1997, p.22.

55 RODRÍGUEZ, César. La decisión judicial: el debate Hart-Dworkin. Bogotá: Siglo del Hombre, 1997, p.23.

56 RODRÍGUEZ, César. La decisión judicial: el debate Hart-Dworkin. Bogotá: Siglo del Hombre, 1997, p.23.

57 RODRÍGUEZ, César. La decisión judicial: el debate Hart-Dworkin. Bogotá: Siglo del Hombre, 1997, p.24. 
das insuficiências da teoria positivista vigente que Hart elabora sua teoria para a reconstrução do positivismo.

Como representante do positivismo jurídico, Hart se propõe a analisar o ordenamento de forma estrutural, a fim de descrever como se dá seu funcionamento, tanto por isso afirma: "minha exposição é descritiva no sentido de que é moralmente neutra e não tem fins de justificativa"58.

Identificar, neste cenário, implica estabelecer distinções para que o direito não seja confundido com outros âmbitos, razão pela qual Hart sublinha que seu intuito é propiciar "uma melhor compreensão das semelhanças e diferenças entre o direito, a coerção e a moral como tipos de fenômenos sociais" 59 , o que se justifica frente à proposta positivista de afastar o reconhecimento da repercussão da moral para a formulação do direito.

A discordância de Ronald Dworkin ${ }^{60}$ em relação à compreensão de direito para Hart, e também no que diz respeito a como o direito deve ser identificado, promove o início do diálogo, materializado pelo ensaio intitulado "Pós-escrito de Hart e a questão da filosofia política"61.

Para Dworkin, a identificação do direito deve pautar-se na interpretação da prática jurídica, não podendo constituir apenas uma descrição neutra, sendo que a implicação disso é justamente a necessidade não só de uma descrição da prática jurídica, mas também de uma justificação moral dessa prática ${ }^{62}$.

Cumpre salientar que o projeto teórico-filosófico de Dworkin é crítico ao positivismo jurídico, sendo que, de maneira expressa, o autor lança o debate com Hart, quando em 1977, ao destacar as insuficiências das respostas desse modelo para os casos difíceis, afirma: "quero lançar um ataque geral contra o positivismo jurídico e usarei a versão de H. L. A. Hart como alvo, quando um alvo específico se fizer necessário". 63

Em oposição à abordagem adotada por Hart, a teoria de Dworkin não se pretende

58 HART, Herbert L. A. O conceito de direito. São Paulo: WMF Martins Fontes, 2009, p.309.

59 HART, Herbert L. A. O conceito de direito. São Paulo: WMF Martins Fontes, 2009, p.22.

60 DWORKIN, Ronald. The philosofy of law. Oxfort: University Press, 1997, p.34.

61 DWORKIN, Ronald. The philosofy of law. Oxfort: University Press, 1997, p.35.

62 DWORKIN, Ronald. The philosofy of law. Oxfort: University Press, 1997, p.34.

63 DWORKIN, Ronald. Levando os direitos a sério. São Paulo: Martins Fontes, 2007, p.35. 
descritiva e neutra, do contrário. A intenção não é apenas descrever, mas também justificar a prática judiciária, que deve ser conduzida levando em conta um conteúdo moral, este que "se insere no direito por meio do uso e argumentação dos princípios jurídicos, notadamente no momento da aplicação normativa"64.

Nesse sentido, Dworkin quer deixar claro é que a tese das fontes, elaborada por Hart, não é neutra na argumentação, pois ela toma posição em casos complexos. Cabe destacar que Hart anui com a seguinte assertiva: "os direitos de ambas as partes devem ser identificados por meio da consulta às fontes tradicionais do direito, isto é, o juiz deve apenas aplicar a lei ao caso, sem nenhuma preocupação de justificação moral" ${ }_{65}$.

A razão pela qual Hart descarta a possibilidade de uma justificação moral do direito diz respeito à necessidade de diferenciação entre esses dois campos, sendo que o autor reconhece a existência de conexões, mas assevera que não existem conexões necessárias entre o conteúdo do direito e a moral ${ }^{66}$. Por isso, não há que se falar em relação de justificação, do contrário, o que se tem é a independência e total dissociação desses campos.

Assim, em clara divergência com Dworkin, Hart frisa que esses campos não são interdependentes, tanto que pode haver direitos e deveres jurídicos que não carecem de nenhuma justificação ou força moral ${ }^{67}$. Segundo Dworkin, fazer tal afirmação significa colocar sob a sombra da contradição a argumentação tecida pelo positivismo.

Para Dworkin, como elucida Hart ao promover sua crítica, "deve haver ao menos fundamentos morais prima facie para as afirmações acerca da existência dos direitos e dos deveres jurídicos" ${ }^{\prime 6}$. O positivismo jurídico, em especial o de Hart, ao

64 COURA, Alexandre de Castro; AZEVEDO, Silvagner. Indeterminação do direito e discricionariedade judicial: pensando a crise do positivismo jurídico a partir de Kelsen, Hart e Dworkin. COURA, Alexandre de Castro; BUSSINGUER, Elda Coelho de Azevedo (Orgs.). Direito, política e constituição: reflexões acerca da tensão entre constitucionalismo e democracia à luz do paradigma do Estado Democrático de Direito. Curitiba: CRV, 2014, p.117.

65 HART, Herbert L. A. Postscriptum. RODRÍGUEZ, César (Org.). La decisión judicial: el debate Hart-Dworkin. Bogotá: Siglo del Hombre, 1997, p.130.

66 HART, Herbert L. A. Postscriptum. RODRÍGUEZ, César (Org.). La decisión judicial: el debate HartDworkin. Bogotá: Siglo del Hombre, 1997, p.130.

67 HART, Herbert L. A. Postscriptum. RODRÍGUEZ, César (Org.). La decisión judicial: el debate HartDworkin. Bogotá: Siglo del Hombre, 1997, p.131.

68 HART, Herbert L. A. Postscriptum. RODRÍGUEZ, César (Org.). La decisión judicial: el debate Hart- 
negar este fundamento e ao pretender ser neutro ao tratar da justificação, adota uma compreensão de mundo "peculiar do essencialismo jurídico" ", ao passo que de maneira prévia reconhece que podem existir direitos e deveres sem nenhuma justificação moral.

Na concepção de Hart, a teoria jurídica deveria "evitar comprometer-se com teorias filosóficas controvertidas acerca da natureza geral dos juízos morais"70, sendo que deve deixar tal questão em aberto. Isso porque deve ficar a cargo do juiz, quando da aplicação do direito, "formular o melhor juízo moral possível, sobre qualquer assunto relacionado com a moral que venha a decidir ${ }^{71}$. Assim, em termos práticos, não haveria nenhuma importância se, ao decidir dado caso, o "juiz está criando direito de acordo com a moral ou se, pelo contrário, é guiado por um juízo moral seu"72.

Com efeito, cabe destacar o desprendimento de Hart no que diz respeito a formulação de um "estatuto objetivo" ${ }^{\prime \prime}$, composto por princípios. Na medida em que sempre que for incitado a decidir e a manejar estas questões, em razão da discricionariedade, que é resta é exigir que o juiz faça uso do "melhor critério moral ao criar uma nova lei"74, o que não converte a moral em uma lei preexistente.

As oposições de Dworkin a respeito dessa compreensão combate não somente a questão da relação do direito com a moral, mas, sobretudo, a própria aceitação da discricionariedade, feita de forma expressa por Hart. Deixar a cargo do critério moral do juiz a decisão, contraria à proposta de Dworkin. Em Hart os casos problemáticos são resolvidos pela afirmação de que "os juízes exercitam seu poder discricionário para decidir esses casos por meio de uma nova legislação"75.

Dworkin. Bogotá: Siglo del Hombre, 1997, p.130.

69 HART, Herbert L. A. Postscriptum. RODRÍGUEZ, César (Org.). La decisión judicial: el debate HartDworkin. Bogotá: Siglo del Hombre, 1997, p.130.

70 HART, Herbert L. A. Postscriptum. RODRÍGUEZ, César (Org.). La decisión judicial: el debate HartDworkin. Bogotá: Siglo del Hombre, 1997, p.111.

71 HART, Herbert L. A. Postscriptum. RODRÍGUEZ, César (Org.). La decisión judicial: el debate HartDworkin. Bogotá: Siglo del Hombre, 1997, p.111.

72 HART, Herbert L. A. Postscriptum. RODRÍGUEZ, César (Org.). La decisión judicial: el debate HartDworkin. Bogotá: Siglo del Hombre, 1997, p.112.

73 HART, Herbert L. A. Postscriptum. RODRÍGUEZ, César (Org.). La decisión judicial: el debate HartDworkin. Bogotá: Siglo del Hombre, 1997, p.111.

74 HART, Herbert L. A. Postscriptum. RODRÍGUEZ, César (Org.). La decisión judicial: el debate HartDworkin. Bogotá: Siglo del Hombre, 1997, p.112.

75 DWORKIN, Ronald. Levando os direitos a sério. São Paulo: Martins Fontes, 2007, p. 35. 
Para Dworkin esse é justamente o "calcanhar de Aquiles do positivismo jurídico, incapaz de oferecer uma resposta adequada à legitima atividade jurisdicional"76, sendo que "os princípios desempenham um papel fundamental nos argumentos que sustentam as decisões a respeito de direitos e obrigações jurídicos particulares" 7 .

Feitas tais considerações, cumpre tratar como essas duas percepções a respeito da relação do direito e moral, bem como as consequências decorrentes de cada modelo, podem ser compreendidas a partir da obra "A mancha humana", de Roth, com vistas a identificar quais as contribuições podem ser proporcionadas pela aproximação com a literatura.

\section{As contribuições da obra "a mancha humana" para o debate entre Hard e Dworkin}

Coleman Silk esconde um segredo. O professor de estudos clássicos no Athena College, na Nova Inglaterra, ocultou de sua mulher, dos seus quatro filhos, dos seus colegas de trabalho e de seu amigo Nathan Zuckerman um segredo durante cinquenta anos. Mas não se trata do segredo do caso que mantém, aos setenta anos, com uma mulher com metade da sua idade e um passado brutalmente devastado. Também não é o segredo do seu alegado racismo, pretexto de alguns rivais para deflagrar uma série de perseguições, que culminaram em seu afastamento da universidade, e, na sua opinião, adoeceu e matou sua mulher. O segredo de Coleman Silk poderia ter the salvado das acusações de racismo, caso fosse revelado. Certamente mudaria a percepção de todos aqueles que o acusavam de discriminar duas alunas, por atribuir a elas o adjetivo de "spooks", termo pejorativo empregado para ofender pessoas negras.

Se revelado, a defesa que Coleman Silk tanto sustentou mediante o conselho composto por seus colegas - a de que empregou essa expressão no outro sentido que esta possui, qual seja, "fantasma", até porque nunca havia visto as referidas

76 COURA, Alexandre de Castro; AZEVEDO, Silvagner. Indeterminação do direito e discricionariedade judicial: pensando a crise do positivismo jurídico a partir de Kelsen, Hart e Dworkin. COURA, Alexandre de Castro; BUSSINGUER, Elda Coelho de Azevedo (Orgs.). Direito, política e constituição: reflexões acerca da tensão entre constitucionalismo e democracia à luz do paradigma do Estado Democrático de Direito. Curitiba: CRV, 2014, p.120.

77 DWORKIN, Ronald. Levando os direitos a sério. São Paulo: Martins Fontes, 2007, p.46. 
alunas, tanto por isso utilizou a expressão - talvez teria sido acatada, evitando seu afastamento e que os fatos de sua vida privada fossem expostos.

Apesar dessas hipóteses, que invariavelmente ocupam as reflexões dos leitores que não entenderam o motivo pelo qual o personagem insiste em esconder este segredo, não é possível saber ao certo se, ao trazer às claras o que tanto ocultou, Coleman Silk seria absolvido ou mais ainda execrado.

É essa dúvida que compõe o dilema vivido por Coleman, talvez a suspeita de ser novamente mal interpretado e perseguido, ou quem sabe o orgulho e o "empenho de levar até o fim todas as decisões"78 o fizeram levar para o túmulo a alegação que poderia significar a salvação de sua reputação.

É Ernestine, irmã de Coleman, que, nos momentos finais do enredo, aparece de forma discreta no velório do irmão, e revela para amigo pessoal do professor, Nathan Zuckerman, o repugnante segredo de uma vida. Logo que Nathan vê Ernestine de longe, a confunde com a esposa de Herb Keble, também professor da universidade de Athena, sendo que a razão da confusão é justamente pelo fato de Ernestine ser também negra.

Depois de se aproximar, no entanto, Nathan descobre que Ernestine é, na verdade, irmã de Coleman, e junto com essa descoberta tantas outras revelações são feitas, dentre elas a principal: apesar da pele clara, Coleman Silk era negro, descendia de uma família de mãe e pai negros, e nascera com um tom de pele um pouco mais clara, o que Ihe permitiu alistar-se na marinha, quando jovem, declarando-se branco e negando toda sua descendência familiar. Fora "enterrado como judeu, morto como um judeu branco"79, quando na verdade não o era.

Abandonou sua mãe e irmãos para construir sua nova identidade distante do preconceito sofrido pelos negros nos Estados Unidos em 1953, o que despertou a ira de seu irmão, "primeiro por causa do que Coleman fez a mãe, e segundo porque naquele tempo havia uma luta a travar e Coleman não quis travá-la"80.

É justamente esse segredo que torna a acusação de racismo feita contra Coleman ainda mais inapropriada, mas como esse "homem que decide forjar um destino 78 ROTH, Philip. A mancha humana. 10. ed. Alfragide: Dom Quixote, 2014, p.341.

79 ROTH, Philip. A mancha humana. 10. ed. Alfragide: Dom Quixote, 2014, p. 341.

80 ROTH, Philip. A mancha humana. 10. ed. Alfragide: Dom Quixote, 2014, p. 342. 
histórico diferente, que resolve arrombar o ferrolho histórico e o arromba, que consegue modificar brilhantemente a sua sorte pessoal para, afinal, ser apanhado na armadilha do momento presente" 81 , a emboscada da moral.

Mas, ainda assim, apesar de todas as acusações infundadas direcionadas a ele, mal sabiam os algozes que "o seu crime excedia tudo aquilo de que quiseram acusálo"82. Como observa Nathan, seu amigo das últimas horas de vida, "há pessoas que não veem com bons olhos alguém que não respeita as convenções"83, e para o desfavor de Coleman, a diretora do seu departamento, Delphine Roux, era uma dessas pessoas.

Delphine Roux passou a ser uma antagonista empedernida, responsável por revirar e julgar sua vida pessoal, por desprender-se dos fatos, dos possíveis significados da palavra "spooks", por exercer toda discricionariedade que estava à sua disposição para julgá-lo de acordo com os interesses, que ela pressupunha, estarem de acordo com a correição moral merecida por Coleman.

Certamente, a diretora do departamentojulgou "para demarcar um território, onde apenas os bons, ou seja, nós e os nossos iguais, podem habitar" 84 , sendo que tal demarcação pautou-se em uma concepção moral corretiva, que flexiona o direito e os fatos para aplicar uma lição igualmente moral ao suposto transgressor.

Assim, quando a personagem Delphine Roux age dessa forma, tem a "virtude como explicação" 85 , na medida em que assim como "está a mitologia povoada de gigantes, monstros e serpentes, ao defini-lo (Coleman) como um monstro, ela define-se como uma heroína. Essa é a maneira de aniquilar o monstro. Ela quer dar a tudo isso um estatuto moral mitológico"86.

A discricionariedade da diretora do departamento, Delphine Roux, é fruto de uma conjuntura que lhe permite não só fazer a melhor escolha, mas, sobretudo, valorar de acordo com sua concepção de moral corretiva as condutas que lhe são apresentadas.

81 ROTH, Philip. A mancha humana. 10. ed. Alfragide: Dom Quixote, 2014, p. 341

82 ROTH, Philip. A mancha humana. 10. ed. Alfragide: Dom Quixote, 2014, p. 340.

83 ROTH, Philip. A mancha humana. 10. ed. Alfragide: Dom Quixote, 2014, p. 340.

84 PÊPE, Albano Marcos Bastos. O que significa julgar. TRINDADE, André Karam; STRECK, Lenio Luiz (Orgs). Os modelos de juiz: ensaios de direito e literatura. São Paulo: Atlas, 2015, p.17

85 ROTH, Philip. A mancha humana. 10. ed. Alfragide: Dom Quixote, 2014, p. 55.

86 ROTH, Philip. A mancha humana. 10. ed. Alfragide: Dom Quixote, 2014, p.55. 
Essa narrativa marcada pelas ingerências e perseguições de Delphine aproxima-se da proposta de positivismo jurídico elucidado por Hart, que colocou "à disposição da comunidade jurídica o direito como um sistema de regras" 87 , sendo que frente à pluralidade de regras, o positivismo permite que o juiz faça a melhor escolha, o que abre margem para a discricionariedade.

Então, nos casos problemáticos, "os juízes têm e exercitam seu poder discricionário para decidir esses casos por meio de nova legislação"88, exatamente como Delphine, que ignora até mesmo as outras interpretações possíveis para a palavra "spooks", demarcadas de forma exaustiva pelo dicionário, sob o argumento de que "não foi com esse sentido que foi interpretado"89.

A diretora do departamento não só determina qual o sentido único possível, o que lhe serve para condenar a conduta de Coleman, como também exclui todas as outras hipóteses fornecidas pelo dicionário, em nome de "seu indomado espírito persecutório" ${ }^{\prime \prime}$.

A compreensão de Hart é receptiva à discricionariedade e deposita nesta escolha a ser feita pelo magistrado a solução para tratar das circunstâncias em que o ordenamento não prevê, por meio de regras, ditames para solucionar o caso concreto posto. Para essa acepção, discricionária, o cenário para atuação de Delphine é possível, pois "deixam de haver critérios, para só haver opiniões"91.

Ademais, "sob a lógica positivista, um princípio não é norma porque ele trata de uma espécie de adereço do direito"92, razão pela qual o próprio Hart reconhece no Postscriptum, que sua teoria carece de um tratamento detalhado dos princípios ${ }^{93}$, ponto essencial que, ao fim, conduz ao problema da relação ou do vínculo entre direito e moral. De todo modo, seguindo a concepção positivista, Hart justifica a ausência de apego a esta distinção, dado que "as regras e princípios guardam

87 STRECK, Lenio Luiz. Verdade e consenso: constituição, hermenêutica e teorias discursivas. 4.ed. São Paulo: Saraiva, 2012, p.225.

88 DWORKIN, Ronald. Levando os direitos a sério. São Paulo: Martins Fontes, 2007, p.46.

89 ROTH, Philip. A mancha humana. 10. ed. Alfragide: Dom Quixote, 2014, p.99.

90 ROTH, Philip. A mancha humana. 10. ed. Alfragide: Dom Quixote, 2014, p. 107.

91 ROTH, Philip. A mancha humana. 10. ed. Alfragide: Dom Quixote, 2014, p. 346.

92 STRECK, Lenio Luiz. Verdade e consenso: constituição, hermenêutica e teorias discursivas. 4.ed. São Paulo: Saraiva, 2012, p.58.

93 RODRÍGUEZ, César. La decisión judicial: el debate Hart-Dworkin. Bogotá: Siglo del Hombre, 1997, p.53. 
diferenças importantes, mas entre eles não existe uma separação tangente" ${ }^{\prime \prime 4}$.

A proposta de Dworkin é diametralmente oposta, tendo em vista o destaque dado aos princípios, os quais "representam um papel fundamental nos argumentos que sustentam as decisões a respeito de direitos e obrigações jurídicos particulares" ${ }^{\prime 95}$. Nesse sentido, Dworkin, "refuta, então, que, dentre as possibilidades de solução da contenda, a escolha da decisão jurídica seja feita através de uma escolha discricionária do julgador"96.

A sustentação propiciada pelos princípios é relevante justamente porque o "juiz não é livre para adotar o padrão que lhe convier, mas tem o dever de chegar a uma compreensão"97 justificada por princípios. Para sua abordagem, faz-se essencial, portanto, a compreensão acerca do que são princípios, bem como a diferenciação destes frente às regras.

Em linhas gerais, as regras seguem uma lógica de aplicação distinta dos princípios, qual seja, a do "tudo ou nada", pois "dados os fatos que uma regra estipula, então ou a regra é válida, e nesse caso a resposta que ela oferece deve ser aceita, ou não é válida, e neste caso em nada contribui para a decisão"98.

Em razão dessa necessidade de adequação, o enunciado da regra deve destrinchar de forma pormenorizada as possibilidades de aplicação, podendo ter exceções, desde que estas sejam enumeradas, listadas ${ }^{99}$. Já no que concerne aos princípios, os enunciados descritivos responsáveis por delimitar as hipóteses de aplicação não existem, posto que os princípios "não apresentam consequências jurídicas que se seguem automaticamente quando as condições são dadas"100.

Estes, diferentemente das regras, dependem de uma decisão particular, guiada pela razão enunciada pelo princípio, o qual conduz o argumento em certa direção ${ }^{101}$, sendo que, quando tais princípios se entrecruzam, diferentemente do que ocorre com as regras, estes não são expurgados do ordenamento jurídico. 94 RODRÍGUEZ, César. La decisión judicial: el debate Hart-Dworkin. Bogotá: Siglo del Hombre, 1997, p.53. 95 DWORKIN, Ronald. Levando os direitos a sério. São Paulo: Martins Fontes, 2007, p.46.

96 MOREIRA, Nelson Camatta; TOVAR, Leonardo Z. Hermenêutica e decisão Judicial: em busca de respostas adequadas à Constituição. Derecho y Cambio Social, v. 40, p. 01-33, 2015, p.23.

97 DWORKIN, Ronald. Levando os direitos a sério. São Paulo: Martins Fontes, 2007, p.430.

98 DWORKIN, Ronald. Levando os direitos a sério. São Paulo: Martins Fontes, 2007, p.39.

99 DWORKIN, Ronald. Levando os direitos a sério. São Paulo: Martins Fontes, 2007, p.39.

100 DWORKIN, Ronald. Levando os direitos a sério. São Paulo: Martins Fontes, 2007, p.40.

101 DWORKIN, Ronald. Levando os direitos a sério. São Paulo: Martins Fontes, 2007, p.41. 
Por possuírem "a dimensão de peso ou importância"102, não seguem a lógica do "tudo ou nada" das regras, nos casos de conflito de dois princípios, e eventual aplicação de um deles, o outro permanece no ordenamento, tendo em vista que é necessário levar em conta a "força relativa de cada um"103.

É por intermédio dos princípios que o tratamento da questão do direito e da moral se altera em relação à teoria de Hart e Dworkin. Isso porque, para a concepção positivista de Hart, os princípios são opacos, não adquirindo papel relevante para a formulação de sua proposta teórica, sendo que o mesmo se aplica à questão da moral, igualmente relegada pelo positivismo jurídico, que a compreende como campo diverso do direito, regido por uma lógica distinta.

Nesse sentido, a moral, antes "expulsa pelo positivismo, retorna - agora como uma necessidade -, não mais como corretiva/autônoma, e, sim, traduzindo as insuficiências do direito que o positivismo pretendia que fossem dar conta do mundo, a partir do mundo das regras"104.

Essa reaproximação pauta-se pela superação da moral como uma instância corretiva ${ }^{105}$, em razão de contingências históricas, dando lugar à institucionalização da moral no direito, "a partir do direito gerado democraticamente", sendo que "essa transição da moral para o direito somente poderia se dar a partir de uma intersubjetividade reconhecedora de direitos recíprocos na sociedade"106.

É justamente essa virada, que consiste em ponto crucial de distinção entre a compreensão de Hart e Dworkin em relação à moral, posto que ocorreu uma "superação das concepções positivistas a partir da reinserção da moral no direito"107, o que se operacionaliza principalmente por intermédio dos princípios, igualmente desqualificados para a concepção positivista ${ }^{108}$.

102 DWORKIN, Ronald. Levando os direitos a sério. São Paulo: Martins Fontes, 2007, p.42.

103 DWORKIN, Ronald. Levando os direitos a sério. São Paulo: Martins Fontes, 2007, p.42.

104 STRECK, Lenio Luiz. Verdade e consenso: constituição, hermenêutica e teorias discursivas. 4.ed. São Paulo: Saraiva, 2012, p.229.

105 STRECK, Lenio Luiz. Verdade e consenso: constituição, hermenêutica e teorias discursivas. 4.ed. São Paulo: Saraiva, 2012, p.229.

106 STRECK, Lenio Luiz. Verdade e consenso: constituição, hermenêutica e teorias discursivas. 4.ed. São Paulo: Saraiva, 2012, p.228.

107 STRECK, Lenio Luiz. Verdade e consenso: constituição, hermenêutica e teorias discursivas. 4.ed. São Paulo: Saraiva, 2012, p.230.

108 MOREIRA, Nelson Camatta; SOARES, Paulo Vitor L. Saiter. Um breve ensaio sobre a relação entre direito e moral na jurisdição constitucional brasileira à luz da obra medida por medida, de William Shakespeare. Revista de Derechos Humanos y Estudios Sociales, v. 15, p. 65-100, 2016, p.70. 
Cabe ressalvar que, apesar dos princípios constituírem uma espécie de porta de entrada para esta reaproximação, isso também se estende às regras, tendo em vista que as regras não "subsistem autonomamente, como se fosse possível isolar o direito no interior da regra (purificada da moral)"109.

Por tais razões, a relação que Dworkin estabelece é de "justificação moral", na medida em que, inevitavelmente, seguindo a lógica do Estado Democrático de Direito, a identificação do direito não pode constituir uma descrição neutra, como propõe Hart, na medida em que a implicação disso é justamente a necessidade não só de uma descrição da prática jurídica, mas também de uma justificação moral dessa prática ${ }^{110}$, com vistas a afastar a discricionariedade.

Neste ponto, a narrativa de Philip Roth contribui para que sejam evidenciadas até as últimas instâncias as consequências de um discurso moral pautado na pretensão corretiva do direito, que diferentemente da proposta elucidada por Dworkin, impõe de forma discricionária percepções que contrariam até mesmo as convenções já estabelecidas, em nome de sua proposta disciplinatória, como se vê:

[Coleman] As palavras têm significados. Porque, se consultarmos o dicionário, o que encontramos como primeiro significado de spook? Como significado principal? "1.Informal, um fantasma; espectro". [Delphine] Mas, Silk, não foi com esse sentido que foi interpretado. Permita-me que leia o segundo significado: "2. Depreciativo, um negro". Foi com esse sentido que foi interpretado, e o senhor pode compreender a lógica da frase: "alguém as conhece ou são negras que vocês não conhecem?" E é este o significado que irei adotar, nenhum outro se não este. [Coleman] Mas como podia saber que eram estudantes negras se nunca lhes pusera os olhos em cima e, excetuando os seus nomes, não sabia nada a seu respeito? O que sabia, incontestavelmente, era que elas eram estudantes invisíveis, e a palavra para invisível, para fantasma, para espectro é a que eu usei no seu significado principal: spook. ${ }^{111}$.

É dessa discricionariedade aceita pelo positivismo jurídico de Hart, e refutada pela compreensão proposta por Dworkin, que Coleman Silk tenta defender-se, sem sucesso, pois estava a cargo da então julgadora Delphine aprisionar até mesmo os significados das palavras, subordinando aos seus interesses, condicionados a prejudicar, de alguma forma, por questões pessoais, o então colega Coleman Silk.

109 STRECK, Lenio Luiz. Verdade e consenso: constituição, hermenêutica e teorias discursivas. 4.ed. São Paulo: Saraiva, 2012, p.230.

110 DWORKIN, Ronald. Levando os direitos a sério. São Paulo: Martins Fontes, 2007, p.34.

111 ROTH, Philip. A mancha humana. 10. ed. Alfragide: Dom Quixote, 2014, p. 55. 
Esses interesses que não podem ser declarados, pois são totalmente dissociados de uma pretensão legítima de julgamento justo, encontram campo fértil quando o paradigma que se aceita é o da naturalização da discricionariedade ${ }^{112}$, para decidir casos como esse, que "levantam questões tão delicadas, nunca antes apreciados pela reitoria"113.

Desta feita, para enfrentamento dessas situações, que podem ser classificadas de forma provisória como "casos difíceis", compreender a questão dos princípios é temática de primeira ordem, cuja argumentação vincula-se a uma "amálgama de práticas, nos quais as implicações da história legislativa e judiciária aparecem juntamente com apelos às práticas e formas de compreensão partilhadas pela comunidade"114.

O conteúdo normativo dos princípios é formulado, portanto, mediante "uma convivência intersubjetiva que emana dos vínculos existentes na moralidade política da comunidade"115. Não se trata de conceitos puramente abstratos oriundos de uma "operação semântica ficcional"116, muito menos dos valores do julgador em questão, a serem manifestados quando do exercício do seu "melhor juízo moral"117.

A garantia dada a Coleman, a partir da perspectiva de Dworkin, que lhe foi sonegada em razão da manifestação de um paradigma positivista de Delphine, pautado na naturalização da discricionariedade, é justamente que na apreciação das acusações direcionadas a ele, juízo moral nenhum poderia encontrar esteio se não fossem construídos a partir de uma "convivência intersubjetiva que emana dos vínculos existentes na moralidade política da comunidade"118.

Dessa forma, os princípios são, antes de tudo, compartilhados por dada comunidade, "são vivenciados por aqueles que participam da comunidade política

112 STRECK, Lenio Luiz. Hermenêutica Jurídica e(m) Crise: uma exploração hermenêutica da construção do Direito. 10. ed. Porto Alegre: Livraria do Advogado, 2011, p.56.

113 ROTH, Philip. A mancha humana. 10. ed. Alfragide: Dom Quixote, 2014, p. 45.

114 DWORKIN, Ronald. Levando os direitos a sério. São Paulo: Martins Fontes, 2007, p.58.

115 STRECK, Lenio Luiz. Verdade e consenso: constituição, hermenêutica e teorias discursivas. 4.ed. São Paulo: Saraiva, 2012, p.57.

116 STRECK, Lenio Luiz. Verdade e consenso: constituição, hermenêutica e teorias discursivas. 4.ed. São Paulo: Saraiva, 2012, p.57.

117 HART, Herbert L. A. Postscriptum. RODRÍGUEZ, César (Org.). La decisión judicial: el debate HartDworkin. Bogotá: Siglo del Hombre, 1997, p.111.

118 STRECK, Lenio Luiz. Verdade e consenso: constituição, hermenêutica e teorias discursivas. 4.ed. São Paulo: Saraiva, 2012, p.57. 
e que determinam a formação comum da sociedade"119, o que constitui o principal motivo pelo qual tais princípios são elevados ao status constitucional, porque são, sobretudo, deontológicos ${ }^{120}$, e seguem uma lógica binária de aplicação.

Assim, são também uma forma de contestar a discricionariedade, e não naturalizála como consequência inevitável para resolver os casos difíceis, se é que estes podem ser assim classificados, em face da particularidade e da complexidade característica de qualquer caso concreto. Para essa análise, que pretende analisar as consequências da prevalência da discricionariedade, e consequentemente da compreensão de Hart, a literatura se faz instância muito pertinente.

Diante da trama apresentada na obra de Roth, que revela em seus ricos personagens as angústias na existência humana, é plenamente possível relacionar a conduta de Delphine, como "autêntica hartiana", quando se arvora na condição de dona do sentido, atribuindo um sentido unívoco das palavras.

Ao explorar as minúcias da atitude de Delphine, suas pretensões não declaradas aos personagens, mas narradas para o leitor: "fragiliza os pretensos saberes positivos sobre os quais o direito tenta apoiar sua própria positividade"121, neste caso, a discricionariedade. Ao passo que as consternações de Dworkin podem ser verificadas tanto na cruzada defensiva de Coleman Silk, para provar a necessidade de interpretar os possíveis sentidos da palavra spooks; quanto na perplexidade de Ernestine, que questiona a ausência de qualquer critério quando da avaliação da conduta de Coleman, já que "não existem critérios, e sim opiniões"122.

Essa trama atende sobremaneira a proposta do presente estudo de discutir as relações entre direito e moral a partir das contribuições ofertadas por estes personagens literários, os quais auxiliam fundamentalmente na formulação e na elucidação das questões relativas, principalmente a discricionariedade.

Por todo exposto, dentre as tantas contribuições advindas da aproximação do direito e da literatura para a compreensão das relações do direito e da moral na perspectiva do debate de Hart e Dworkin, é esse empreendimento crítico que define a relação entre 119 STRECK, Lenio Luiz. Verdade e consenso: constituição, hermenêutica e teorias discursivas. 4.ed. São Paulo: Saraiva, 2012, p.57.

120 STRECK, Lenio Luiz. Verdade e consenso: constituição, hermenêutica e teorias discursivas. 4.ed. São Paulo: Saraiva, 2012, p.57.

121 OST, François. Contar a lei: as fontes do imaginário jurídico. São Leopoldo: UNISINOS, 2004, p.15.

122 ROTH, Philip. A mancha humana. 10. ed. Alfragide: Dom Quixote, 2014, p. 346. 
esses campos como dialética, ao passo que é pautado pela construção e desconstrução, pois a literatura abre caminhos para a reformulação e, consequentemente, a desnaturalização, o que por vezes ocorre de forma despretensiosa.

\section{CONSIDERAÇÕES FINAIS}

A literatura pode ser compreendida como um laboratório experimental, na medida em que é instância exploradora, por excelência, da condição humana e das consequências advindas da imprevisibilidade da ação dos indivíduos. Assim, esse locus se atém não só à narrativa dos fatos, mas trabalha nos meandros psicológicos dos personagens que compõem dado enredo, desvelando e ocultando a intencionalidade e os sentimentos que determinam as ações.

A aproximação com a obra literária, a "A mancha humana", de Philip Roth, se faz justamente no intento de desfrutar desse potencial associativo e explorador da condição humana, que auxilia na compreensão da temática relacionada ao direito e à moral e transforma o enredo desta história em instância privilegiada para demonstrar as consequências e os conceitos apresentados por Hart e Dworkin, principalmente no que concerne à problemática decorrente da discricionariedade.

Nesta medida, contestar as convenções, exercer o papel crítico por meio do cômico e do paradoxo, liberar as utopias, pôr em xeque as certezas, explorar todas as soluções possíveis, propiciar a abertura para novos questionamentos e narrar as complexidades que envolvem os fatos e os sujeitos são algumas das contribuições ofertadas pela literatura para este estudo.

Ademais, pertine ser considerado como contributo maior a perspectiva multidimensionalviabilizada pelodiscursoliterário determinante paraanalisartanto a proposta de Hart quanto a de Dworkin a respeito da compreensão das relações do direito e da moral, especialmente no que diz respeito à discricionariedade manifestada na atuação de Delphine Roux, e as consequências drásticas para a vida de Coleman Silk.

Não se pode perder de vista que tanto a percepção de Hart quanto a de Dworkin 
ao tratar da questão do direito e da moral e na própria construção de suas respectivas teorias contam o direito. Isto é, as respostas concedidas por Hart e Dworkin evidenciam à constituição do conceito de direito caminhos possíveis para o desafio de estabelecer as relações e os distanciamentos entre o direito e a moral, cujas consequências são, principalmente, relacionadas com a repercussão da discricionariedade.

Neste contexto, a narrativa literária materializa hipóteses e cogita o incogitável, sendo essa a premissa que permitiu a escolha da obra de Roth como palco privilegiado para materializar os argumentos tanto de Hart quanto de Dworkin, bem como suas respectivas consequências para a teoria do direito.

Com efeito, vale recobrar o alerta de que "o jurista que desembarca em terra literária assemelha-se a Colombo pondo os pés no novo mundo - ignorante da natureza exata de sua descoberta"123. E se estas descobertas se mostram reveladoras e, por vezes, resolutivas em um primeiro momento, também não faltam novos abismos abrindo-se a seus pés, os quais renovam o principal atributo da literatura, a ampliação dos horizontes de compreensão, essenciais para a abordagem pretendida neste artigo.

\section{REFERÊNCIAS DAS FONTES CITADAS}

BLAIR, Robert. The grave. New Heaven: Gale Ecco, 2010.

CANDIDO, Antonio. A literatura e a formação do homem. São Paulo: Estrutural, 1972.

COELHO, Nelly Novaes. Literatura e ensino: uma problemática. 2.ed. São Paulo: Ática, 1992.

COURA, Alexandre de Castro; AZEVEDO, Silvagner. Indeterminação do direito e discricionariedade judicial: pensando a crise do positivismo jurídico a partir de Kelsen, Hart e Dworkin. COURA, Alexandre de Castro; BUSSINGUER, Elda Coelho de Azevedo (Orgs.). Direito, política e constituição: reflexões acerca da tensão entre constitucionalismo e democracia à luz do paradigma do Estado Democrático de Direito. Curitiba: CRV, 2014.

DWORKIN, Ronald. The philosofy of law. Oxfort: University Press, 1997.

123 OST, François. Contar a lei: as fontes do imaginário jurídico. São Leopoldo: UNISINOS, 2004, p.58. 
DWORKIN, Ronald. Levando os direitos a sério. São Paulo: Martins Fontes, 2007.

GILCHRIST, Alexandre. Life of William Blake. Cambridge: Cambridge University Press, 2010. GOETHE, Johann Wolfgang Von. Fausto II: uma tragédia. 4.ed. São Paulo: Editora 34, 2015. HART, Hebert L. A. Visita a Kelsen. Lua Nova: Revista de Cultura e Política. São Paulo, 2005. HART, Herbert L. A. O conceito de direito. São Paulo: WMF Martins Fontes, 2009.

HART, Herbert L. A. Postscriptum. RODRÍGUEZ, César (Org.). La decisión judicial: el debate Hart-Dworkin. Bogotá: Siglo del Hombre, 1997.

LANES, Ely Vieitez. Laboratório de literatura. São Paulo: Estrutural, 1978.

MEIRA, Cécil. Introdução ao estudo da literatura. 5.ed. Belém: Imprensa Oficial do Estado, 1988.

MOISÉS, Massaund. Literatura: mundo e forma. São Paulo: Universidade de São Paulo, 1990.

MOREIRA, Nelson Camatta. Direitos e garantias fundamentais e os tratados internacionais de direitos humanos. Belo Horizonte: Fórum, 2012.

MOREIRA, Nelson Camatta; DE PAULA, Rodrigo. Lima Barreto: subcidadania, negação do estado de direito e constitucionalismo dirigente no Brasil. In: MOREIRA, Nelson Camatta. Direito e literatura e os múltiplos horizontes de compreensão pela arte. Ijuí: UNIJUÍ, 2015.

MOREIRA, Nelson Camatta; SOARES, Paulo Vitor L. Saiter. Um breve ensaio sobre a relação entre direito e moral na jurisdição constitucional brasileira à luz da obra medida por medida, de William Shakespeare. Revista de Derechos Humanos y Estudios Sociales, v. 15, p. 65100, 2016.

MOREIRA, Nelson Camatta; TOVAR, Leonardo Z. Hermenêutica e decisão Judicial: em busca de respostas adequadas à Constituição. Derecho y Cambio Social, v. 40, p. 01-33, 2015.

OST. François. Contar a lei: as fontes do imaginário jurídico. São Leopoldo: UNISINOS, 2004.

PÊPE, Albano Marcos Bastos. O que significa julgar. TRINDADE, André Karam; STRECK, Lenio Luiz (Orgs.). Os modelos de juiz: ensaios de direito e literatura. São Paulo: Atlas, 2015.

RODRÍGUEZ, César. La decisión judicial: el debate Hart-Dworkin. Bogotá: Siglo del Hombre, 1997. 
ROTH, Claudia Pierpont. Roth libertado: o escritor e seus livros. São Paulo: Companhia das Letras, 2015.

ROTH, Philip. A mancha humana. 10. ed. Alfragide: Dom Quixote, 2014.

ROTH, Philip. Reading myself and others. Nova York: Vintage International, 2010.

SANCHEZ RUBIO, David. Crítica a una cultura estática y anestesiada de derechos humanos. Por una recuperación por las dimensiones constituyentes de la lucha por los derechos. Derechos y Libertades, Madrid: v. 33, 2015.

STRECK, Lenio Luiz. Hermenêutica Jurídica e(m) Crise: uma exploração hermenêutica da construção do Direito. 10. ed. Porto Alegre: Livraria do Advogado, 2011.

STRECK, Lenio Luiz. Verdade e consenso: constituição, hermenêutica e teorias discursivas. 4.ed. São Paulo: Saraiva, 2012.

Recebido em: dezembro/2016

Aprovado em: julho/2017 